\title{
PERFORMANCE EVALUATION OF SHAFT SPEED CONTROL USING A MAGNETORHEOLOGICAL BRAKE
}

\author{
M.A. Abdullah ${ }^{1}$, A.Z. Zainordin ${ }^{2}$ and K. Hudha ${ }^{3}$ \\ ${ }^{1}$ Faculty of Mechanical Engineering, Universiti Teknikal Malaysia Melaka \\ Hang Tuah Jaya, 76100 Durian Tunggal, Melaka, Malaysia. \\ ${ }^{2}$ Department of Mechanical Engineering, Politeknik Sultan Haji Ahmad Shah, \\ Semambu, 25350 Kuantan, Pahang, Malaysia. \\ ${ }^{3}$ Faculty of Engineering, Universiti Pertahanan Nasional Malaysia, \\ Kem Sungai Besi, 57000 Kuala Lumpur, Malaysia. \\ Email: mohdazman@utem.edu.my'; zaifazlin.poli@1govuc.gov.my²; \\ k.hudha@upnm.edu.my ${ }^{3}$
}

\begin{abstract}
This paper presents a performance evaluation of a shaft speed control using a magnetorheological brake (MR brake). The MR brake consists of a rotating disk that is immersed in magnetorheological fluid (MR fluid). The rheology of the fluid changes under the influence of a magnetic field. Two controllers are proposed in this work: onoff and proportional-integral-derivative (PID). The on-off controller acts as the benchmark controller through computer simulation and experimental testing. Load tests have been considered in order to evaluate the controller's effectiveness in braking the wheel shaft at 50, 100 and $150 \mathrm{~N}$ in varying speeds of 300, 500, 700 and $900 \mathrm{rpm}$. The results obtained in the simulation and the experiment are compared and discussed. The PID controller shows good performance compared to the on-off control where the error percentages of the PID control, which are below 10\%, are lower than the on-off controller.
\end{abstract}

Keywords: Magnetorheological brake; Magnetorheological fluid; braking load; PID control; on-off control.

\section{INTRODUCTION}

Nowadays, drive (throttle, steering and brake) by wire (X-by-wire) systems have improvement potential by minimizing the number of parts used in the system. The $\mathrm{X}$ by-wire system has been employed in several vehicle areas such as vehicle steering, suspension and braking systems [1-5]. The MR (magnetorheological) brake is an X-bywire system that employs MR fluid where the fluid thickens dramatically under the influence of a magnetic field. The MR brake consists of a rotating disc immersed in MR fluid in the enclosure of an electromagnetic coil. The applied magnetic field increases the yield strength of the MR fluid and decreases the rotational speed of the shaft. MR fluid is a smart fluid in which its viscosity is increased when the strength of the magnetic field is increased. MR fluid is made up of micron sized suspensions measuring between 1 and 10 microns. The yield strength of MR fluid can be controlled by changing the strength of the applied magnetic field. The rheological response of MR fluid results from the polarization induced in the suspended particles by application of an external field. The interaction between the resulting induced dipoles causes the 
particles to form a columnar structure, parallel to the applied field. These chain-like structures restrict the motion of the fluid, thereby increasing the viscous characteristics of the fluid. The mechanical energy needed to yield these chain-structures increases as the applied magnetic field increases resulting in a field dependent yield stress. The behavior of controllable fluids is often represented as a Bingham plastic having variable yield strength [5-7].

The application of an MR fluid in a braking system is relatively new. The design and experimental evaluation of an MR brake have been presented and introduced with an amplifying factor to evaluate brake performance [8]The design optimization procedure uses simulated annealing combined with finite element simulations involving magnetostatics, fluid flow and heat transfer analysis [8].Other studies focus on the braking response of inertia/load by using an electro-rheological (ER) brake for ERrobotic applications, in terms of ER braking velocity response, in order to halt the robot arm rapidly [9]. [10]proposed a new MR brake structure using the waveform boundary of a rotary disk generating more resistance torque compared with the conventional MR brake. Furthermore, the MR brake system has been implemented in other applications, such as joysticks, prosthetic knees and artificial muscle manipulators [11]. Through simulation, previous researchers have implemented the sliding mode controller using the MR brake to evaluate optimal wheel slip that shows fast anti-lock braking [12]. This paper discusses the performance evaluation of a controller using an MR brake under various speeds and loads. The aim of this work is to evaluate the performance of a shaft speed control in terms of overshoot and settling time using an MR brake. Two types of controller will be presented: the on-off and the PID. Each controller performs using three caseloads. The outline of this paper is as follows. Section II presents a description of the control strategy of the MR brake system. Section III describes the experimental setup and the MR brake test procedure. Section IV gives the experimental results of the shaft speed control. Finally, the conclusions and recommendations for future work are presented.

\section{CONTROL STRATEGY OF THE MAGNETORHEOLOGICAL BRAKE SYSTEM}

In order to realize the effectiveness of an MR brake, the controller is required to adjust the current in the coil on the brake periodically to maintain the torque. Figure 1 shows the control schematic. In this scheme, two typical control strategies are implemented in the MR brake system based on a classic controller. First, the bang-bang or on-off controller and second a conventional PID controller. The on-off controller is the simplest control referred to as the on-state and the off state. The on-state means that the current is fully applied to the MR brake coil and the off state that no current is applied. In contrast, the PID controller continuously applies the current with different duty cycle times to provide variable current to the MR brake. In order to reach and maintain the desired rotational speed, the maximum current is applied to the MR brake coil when the actual rotational speed is lower than the desired rotational speed, while no current is applied if the actual rotational speed is lower than the desired speed.

The on-off controller algorithm can be expressed in the time domain as:

$$
i(t)=\mathrm{e}(\mathrm{t})\left\{\begin{array}{l}
1, \mathrm{x}<\mathrm{w}_{\text {desired }} \\
0, \mathrm{x}>\mathrm{w}_{\text {desired }}
\end{array}\right.
$$




$$
\begin{gathered}
i(t)=\operatorname{Signe}(t)\left(K_{y}\right) \\
e(t)=w_{\text {desired }}(t)-w_{\text {actual }}(t)
\end{gathered}
$$

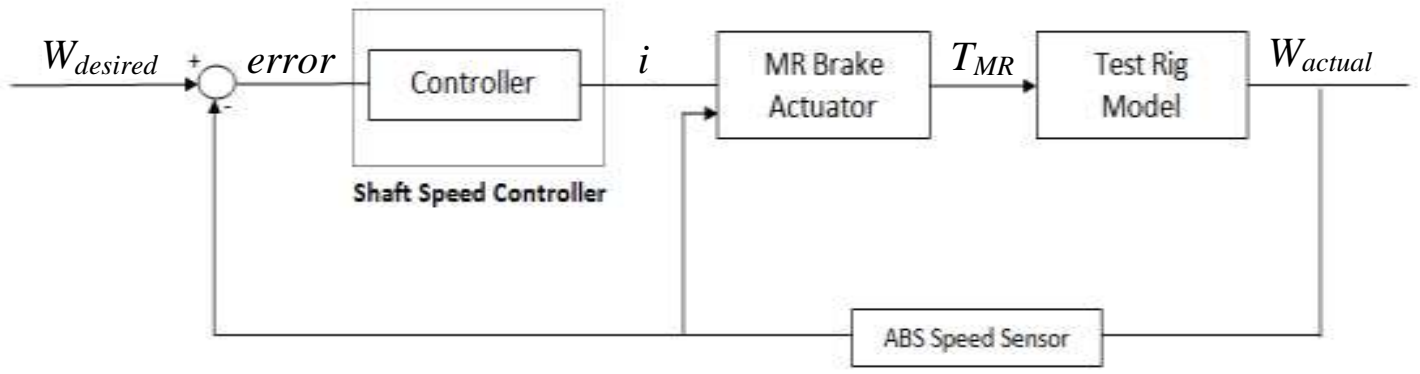

Figure 1. Schematic diagram of the control system.

The value of $K_{y}$ can be assigned based on the system's response to reach the desired value. This value will be assigned as the proportional value for the PID controller. As mentioned in the first section, the proposed controller in this study is a conventional PID controller. The conventional PID controller consists of three parameters, the proportional gain $K_{p}(t)$, the integral gain, $K_{\mathrm{i}}(t)$ and the derivative gain, $K_{\mathrm{d}}(t)$, where the intention of the gains is to correct the error (e)t which is the difference between the desired and actual values. The input current to the MR brake coils is expressed as $i(t)$ such as denoted in Eq. (4).

$$
i(t)=K_{p}(t) e(t)+K_{d}(t) \int e(t) d t+K_{d}(t) \frac{d}{d t} e(t)
$$

The PID controller was designed by an implemented trial and error method and the actual controller is proved by sensitivity analysis. The PID controller systems must operate in a closed-loop system. The proportional parameter is defined and the parameter is already obtained by using the on-off parameter $\left(K_{y}\right)$. The process is continued by adjusting the integral and derivative gains to make the system stable. Furthermore, the trial and error method is an easier way to improve the rise time, steady-state error and overshoot which are the parameters being tweaked. Moreover, adjusting the PID parameters will produce different effects on the system [13].

\section{EXPERIMENTAL SETUP}

An instrumented experimental MR brake test rig was set up as shown in Figure 2. The test rig consists of a three phase electric motor that functions to drive the MR brake shaft where it is coupled via a pulley to an A-type V-belt. The speed from the motor is transmitted to the MR brake shaft using a tensional bearing that is fitted beside the electric motor. Next, the housing of this MR brake is coupled to a load cell via an arm $238 \mathrm{~mm}$ long to measure the braking torque. An antilock brake system (ABS) sensor is used to measure the rotational speed of the MR brake system. The MR brake test rig is equipped with an I/O device, namely an integrated measurement and control (IMC) device that is used to provide signal processing for the sensory system. These signals are digitally processed and stored in a personal computer using the ONLINE FAMOS control software. A DC power supply manufactured by GW-INSTEK is used to supply 
electric currents to the MR brake electromagnetic coil. In this experiment, the current driver is used to amplify the signal coming from the IMC device the output of which is typically less than $0.4 \mathrm{~mA}$, inadequate to magnetize the MR brake coil. The output from the IMC device is connected to the microcontroller in order to generate PWM (pulse width modulation) to drive the current driver and is given continuously to the MR brake coils $[8,10,12]$.

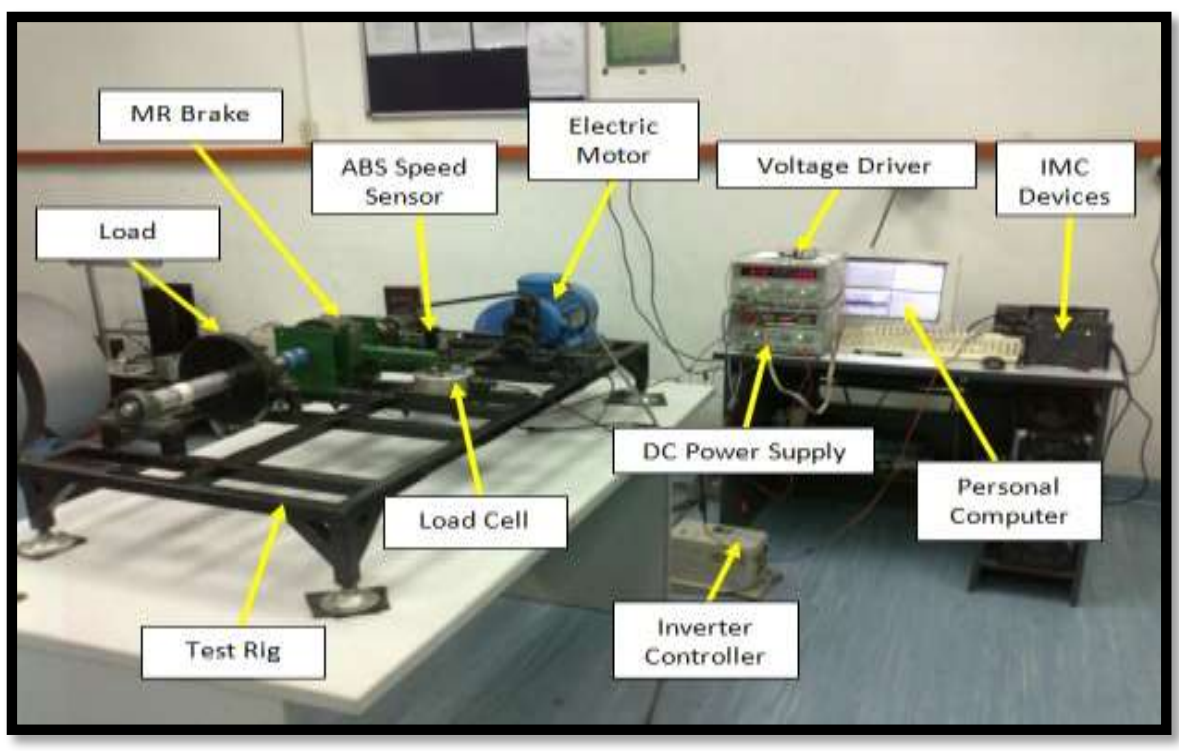

Figure 2. Mechanical assembly of the MR brake test rig.

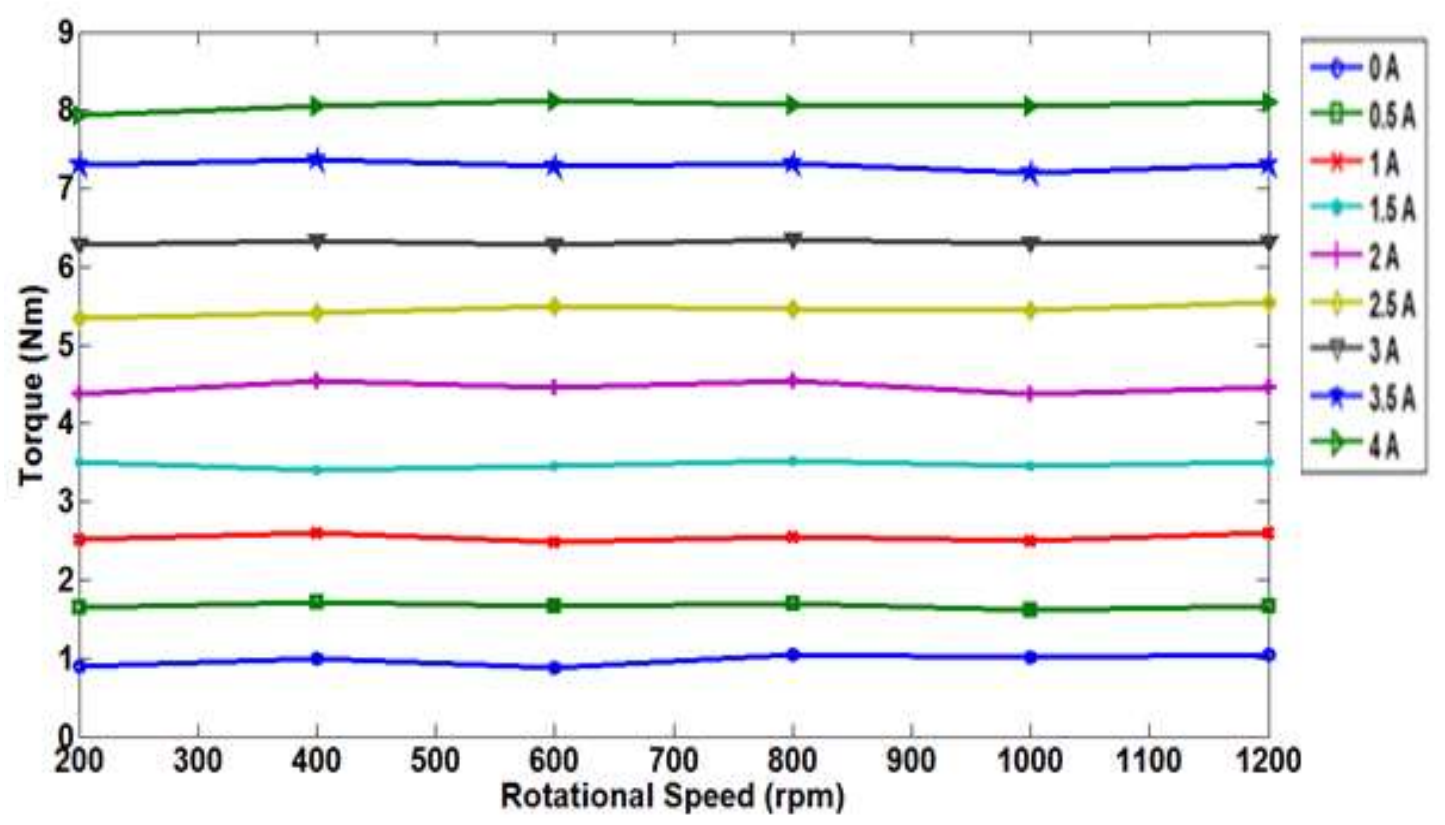

Figure 3. Characteristic of the MR brake.

In this work, the speed from the electric motor is passed continuously to the MR brake shaft where the actual rotational speed is $1200 \mathrm{rpm}$. The electric current applied to the coil will increase the yield stress of the MR fluid and slow the velocity of the shaft until the shaft reaches the desired speed by using the proposed controller. The current is 
given rapidly to the MR brake coils to adjust the yield stress of the MR fluid that will provide the torque that slows the shaft's rotational speed. In the experiment, the desired rotational speed, that is $300 \mathrm{rpm}, 500 \mathrm{rpm}, 700 \mathrm{rpm}$ and $900 \mathrm{rpm}$, is chosen to test the effectiveness of each controller. The $50 \mathrm{~N}, 100 \mathrm{~N}$ and $150 \mathrm{~N}$ loads were attached to every speed and the data has been captured.The characteristics of the MR brake are shown in Figure 3 where it can be seen that the torque generated by MR brake is almost proportional to the applied current and also independent of the input rotational speed. The torque generated by the MR brake corresponds with the change in current, and the rotational speed with the small difference in value of the torque at every speed, as can be seen in the Figure 3.

\section{EXPERIMENTAL RESULTS}

The experiments were carried out with three caseloads, namely $50 \mathrm{~N}, 100 \mathrm{~N}$ and $150 \mathrm{~N}$. In the experiment, the on-off controller is assigned as a benchmark of the PID controller system. The on-off controller is based on reference thresholds. For the PID controller, the controller parameters of $K_{p}, K_{i}$ and $K_{d}$ are set as 44, 0.001 and 0.03, respectively. These parameters were obtained by trial and error through experiments. Thus, the PID control parameters were applied for all cases in the experiment.

The results determined from the experiment are superimposed on each other and the data captured and recorded. The rotational speed responses are compared in terms of overshoot and settling time for all caseloads. Four rotational speeds were controlled and examined to determine the percentage of overshoot and settling time from the desired rotational speed for each load. The experimental results for all cases are superimposed with lines where the solid line is defined as the desired speed, the dash-dot-dash line is denoted as the response of the on-off controller, while the dashed line is described as the response of the PID controller.

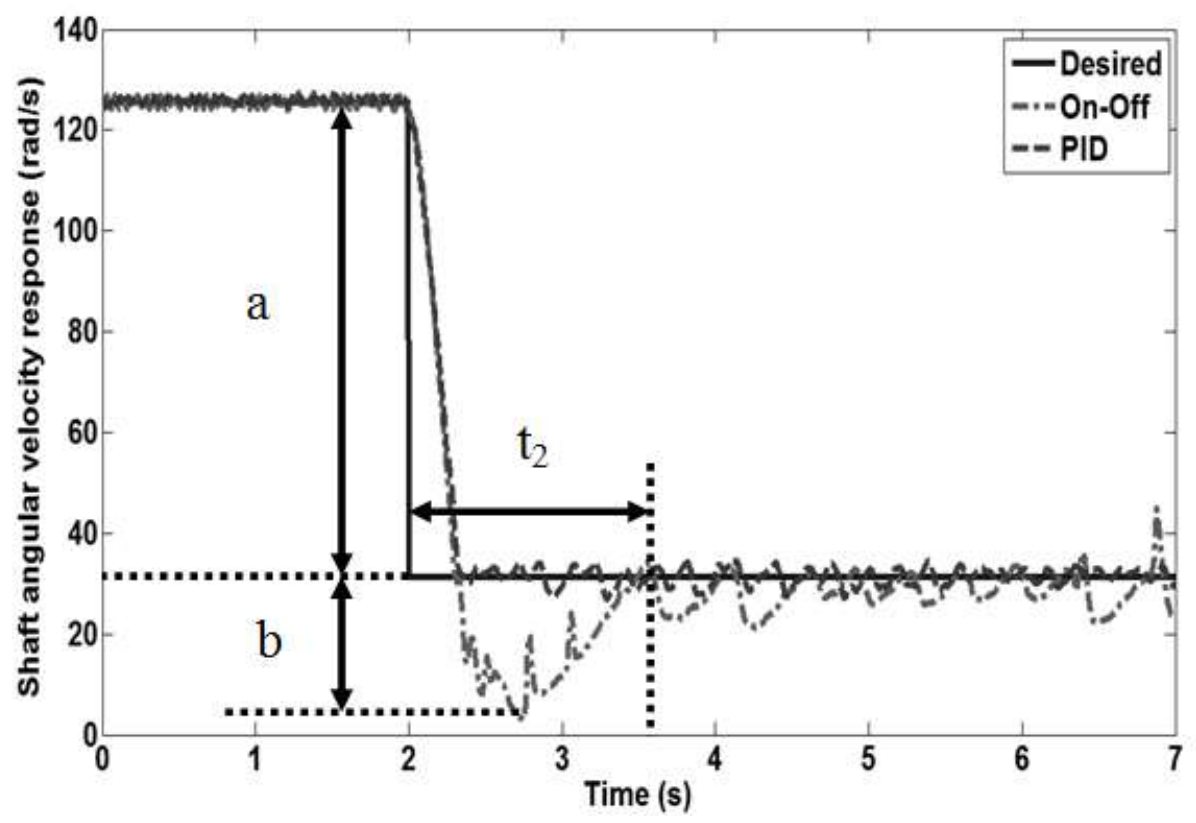

Figure 4. An illustration of overshoot and settling time. 
Figure 4 shows an illustration of the overshoot and settling time of the MR brake shaft speed response. The MR brake performance was evaluated in terms of percentage overshoot and settling time that can be written as:

$$
\begin{gathered}
\% O S=\frac{b}{a} \times 100 \\
\% S T=\frac{t_{2}-t_{1}}{t_{1}} \times 100
\end{gathered}
$$

where:-

$b=$ shaft speed response reduced to the target speed or desired speed

$a=$ shaft speed response exceeding the target

$t_{1}=$ start time (trigger time)

$t_{2}=$ end time (time taken to reach desired speed).

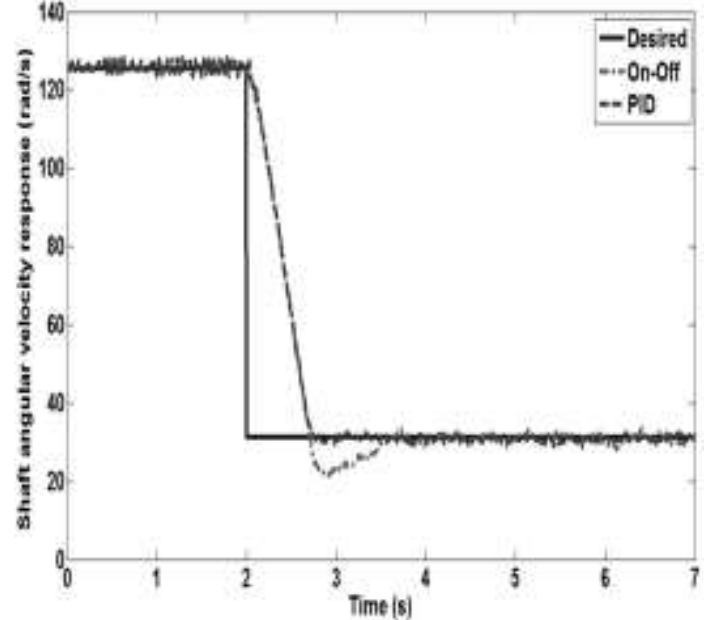

(a) $125.68 \mathrm{rad} / \mathrm{s}-31.42 \mathrm{rad} / \mathrm{s}$

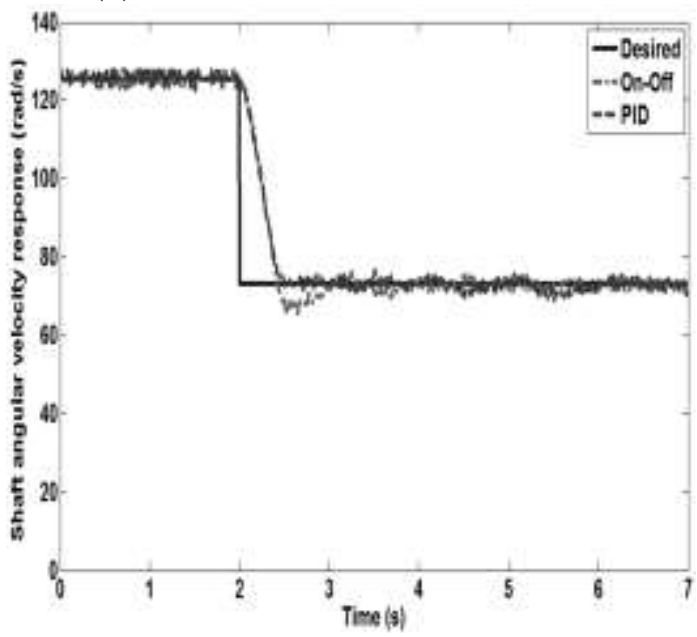

(c) $125.68 \mathrm{rad} / \mathrm{s}-73.31 \mathrm{rad} / \mathrm{s}$

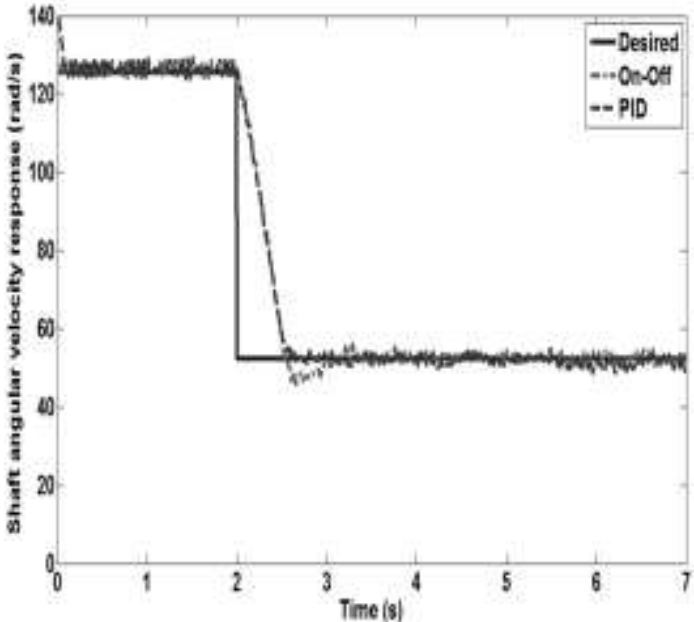

(b) $125.68 \mathrm{rad} / \mathrm{s}-52.37 \mathrm{rad} / \mathrm{s}$

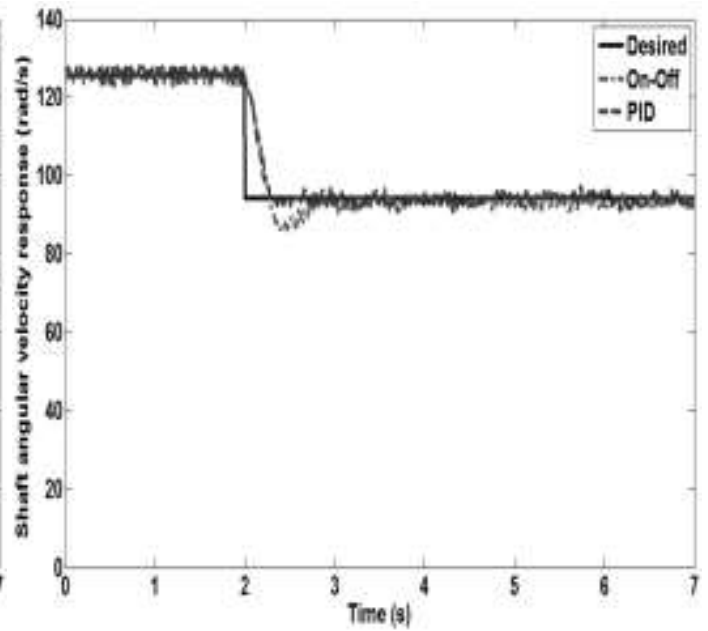

(d) $125.68 \mathrm{rad} / \mathrm{s}-94.26 \mathrm{rad} / \mathrm{s}$

Figure 5.Comparison of the on-off and the PID controller for the shaft speed response for the $150 \mathrm{~N}$ load. 
The data from the experiments were captured between each controller and discussed. $b$ is the target speed, $a$ is the over target speed, $t_{1}$ is the trigger time and $t_{2}$ is the end time for all cases of speed and load. Next, the experimental data were superimposed and the data recorded. The experimental results of the shaft angular velocity response superimposed between the controllers at various loads are shown in Figure 5. From this figure, it can be observed that the angular velocity response using the PID controller is better than that of the on-off controller. The shaft speed response with three caseloads are superimposed over each other and plotted from the actual speed to reach the desired speed/target speed. This will be undertaken using two types of controller, the on-off and PID, assigned to the IMC software device command. The results obtained are from the shaft speed responses of the three cases in terms of the overshoot and settling time data. Figure 5 shows the same decreasing trend for each caseload. The difference is that the shaft speed response exceeds the target when the onoff controller is used compared with the PID controller, showing that the on-off controller produced a higher overshoot of 10 to $20 \mathrm{rad} / \mathrm{s}$ for all shaft speeds. The PID controller performance is better than the on-off controller in reaching the target speed with a small error and settling time. The performance of the on-off and PID controllers is discussed.

Table 1. Data for comparison of the percentage overshoot (\%OS) between the on-off and PID controllers for $50 \mathrm{~N}, 100 \mathrm{~N}$ and $150 \mathrm{~N}$.

\begin{tabular}{|c|c|c|c|c|}
\hline Desired Angular Speed ( $\mathrm{rad} / \mathrm{s})$ & On-Off & $\% \mathrm{OS}$ & PID & $\% \mathrm{OS}$ \\
\hline \multicolumn{5}{|c|}{ For $50 \mathrm{~N}$} \\
\hline $31.42(a)$ & 10 & 22.7 & 30 & 1.5 \\
\hline $52.37(b)$ & 34.4 & 24.5 & 50.5 & 2.6 \\
\hline $73.31(\mathrm{c})$ & 58.8 & 27.7 & 71.5 & 3.5 \\
\hline $94.26(d)$ & 79 & 48.6 & 92.6 & 5.3 \\
\hline \multicolumn{2}{|c|}{ Mean absolute percentage error } & 30.9 & & 3.2 \\
\hline \multicolumn{5}{|c|}{ For $100 \mathrm{~N}$} \\
\hline 31.42 & 21.5 & 10.5 & 30.1 & 1.4 \\
\hline 52.37 & 43.2 & 12.5 & 50.9 & 2 \\
\hline 73.31 & 61.7 & 22.2 & 72.3 & 1.9 \\
\hline 94.26 & 83.1 & 35.5 & 92.2 & 6.6 \\
\hline Mean absolute percentage error & & 20.2 & & 3.0 \\
\hline \multicolumn{5}{|c|}{ For $150 \mathrm{~N}$} \\
\hline 31.42 & 21.8 & 10.2 & 30.1 & 1.4 \\
\hline 52.37 & 43.9 & 11.6 & 51.1 & 1.7 \\
\hline 73.31 & 65.5 & 14.9 & 72.3 & 1.9 \\
\hline 94.26 & 86.2 & 25.7 & 92.5 & 5.6 \\
\hline Mean absolute percentage error & & 15.6 & & 2.7 \\
\hline
\end{tabular}


The summarized performance evaluation of the shaft speed control using the MR brake is given in Table 1. The percentage overshoot between the on-off and PID controller is compared at various loads and speeds. From the table, it is clearly seen that the PID controller shows better performance compared with the on-off controller. The acceptable error for the controller is below 10\%. From the table, the mean absolute percentages for the PID controller are $3.2 \%$ for $50 \mathrm{~N}, 3.0 \%$ for $100 \mathrm{~N}$ and $2.7 \%$ for $150 \mathrm{~N}$ compared to the on-off controller at $30.9 \%$ for $50 \mathrm{~N}, 20.2 \%$ for $100 \mathrm{~N}$ and 15.6 $\%$ for $150 \mathrm{~N}$. The reduction in the percentage values is due to the limitation of the MR brake to produce torque. However, the PID controller shows better performance in reaching the desired speed with a small of error.

Table 2. Data for comparison of the percentage settling time (\%ST) between the on-off and PID controllers for $50 \mathrm{~N}, 100 \mathrm{~N}$ and $150 \mathrm{~N}$.

\begin{tabular}{|c|c|c|c|c|c|}
\hline $\begin{array}{l}\text { Desired Angular } \\
\text { Speed(rad/s) }\end{array}$ & $\begin{array}{l}\text { Desired } \\
\text { Time (s) }\end{array}$ & On-Off & $\% \mathrm{ST}$ & PID & $\%$ ST \\
\hline \multicolumn{6}{|c|}{ For $50 \mathrm{~N}$} \\
\hline 31.42 (a) & 2 & 3.45 & 72.5 & 2.47 & 23.5 \\
\hline $52.37(b)$ & 2 & 2.8 & 40 & 2.4 & 20 \\
\hline $73.31(\mathrm{c})$ & 2 & 2.73 & 36.5 & 2.35 & 17.5 \\
\hline $94.26(d)$ & 2 & 2.59 & 29.5 & 2.2 & 10.4 \\
\hline \multicolumn{3}{|c|}{ Mean absolute percentage error } & 44.6 & & 17.9 \\
\hline \multicolumn{6}{|c|}{ For $100 \mathrm{~N}$} \\
\hline 31.42 & 2 & 3.25 & 62.5 & 2.7 & 35 \\
\hline 52.37 & 2 & 3.11 & 55.5 & 2.6 & 30 \\
\hline 73.31 & 2 & 2.85 & 42.5 & 2.5 & 25 \\
\hline 94.26 & 2 & 2.65 & 32.5 & 2.4 & 20 \\
\hline \multicolumn{3}{|c|}{ Mean absolute percentage error } & 48.3 & & 27.5 \\
\hline \multicolumn{6}{|c|}{ For $150 \mathrm{~N}$} \\
\hline 31.42 & 2 & 3.75 & 87.5 & 2.85 & 42.5 \\
\hline 52.37 & 2 & 3.1 & 55 & 2.73 & 36.5 \\
\hline 73.31 & 2 & 3.05 & 52.5 & 2.61 & 30.5 \\
\hline 94.26 & 2 & 2.9 & 45 & 2.52 & 26 \\
\hline \multicolumn{3}{|c|}{ Mean absolute percentage error } & 60 & & 33.9 \\
\hline
\end{tabular}

The comparison of the on-off and PID controllers in terms of settling time is also evaluated. The time taken for each load to reach consistency at the desired speed is compared between the controllers under various loads and speeds. Table 2 shows the captured summarized settling times for each controller. Using the PID controller, the settling times are lower than those of the on-off controller. This means that the absolute percentage error for the settling time using the PID controller is $17.9 \%$ for $50 \mathrm{~N}, 27.5$ $\%$ for $100 \mathrm{~N}$ and $33.9 \%$ for $150 \mathrm{~N}$ of load compared to the on-off controller that has worse settling times in reaching the desired speed of the PID controller. The percentage errors for the on-off controller are $44.6 \%$ for $50 \mathrm{~N}, 48.3 \%$ for $100 \mathrm{~N}$ and $60 \%$ for 150 
$\mathrm{N}$. Moreover, the increasing load will cause the torque to become saturated as the percentage error for settling time increases.

\section{CONCLUSIONS}

The shaft speed control performance using the MR brake was tested using two types of controller: the on-off and the PID. The results obtained from the experiments with each controller are compared and divided into three load cases. The PID controller shows good performance compared to the on-off control. The error percentages of the PID control are below $10 \%$ which is lower than those of the on-off controller. However, the settling time increases when the load is increased. This is due to the MR brake being limited in producing the braking torque. This brake can be implemented in other applications such as exercise machines, conveyer belts and in other applications where minimum torque is required to control the rotational speed.

\section{ACKNOWLEDGEMENTS}

The authors gratefully acknowledged the Advanced Vehicle Technology (AcTiVe) research group of Centre for Advanced Research on Energy (CARe), the financial support from Universiti Teknikal Malaysia Melaka (UTeM) under Short Term Research Grant no.: PJP/2014/FKM(10A) /S01330 and Fundamental Research Grant Scheme (FRGS), grant no.: FRGS/2013/FKM/TK06/02/2/F00165.

\section{REFERENCES}

[1] Park Y, Jung I. Semi-active steering wheel for steer-by-wire system. SAE Technical Paper No. 2001-01-3306; 2001.

[2] Hudha K, Jamaluddin H, Samin P, Rahman R. Effects of control techniques and damper constraint on the performance of a semi-active magnetorheological damper. International Journal of Vehicle Autonomous Systems. 2005;3:230-52.

[3] Zainordin AZ, Abdullah MA, Hudha K. Modelling and validation of magnetorheological brake responses using parametric approach. IOP Conference Series: Materials Science and Engineering: IOP Publishing; 2013; 012038.

[4] Park EJ, da Luz LF, Suleman A. Multidisciplinary design optimization of an automotive magnetorheological brake design. Computers and Structures. 2008;86:207-16.

[5] Karakoc K, Park EJ, Suleman A. Design considerations for an automotive magnetorheological brake. Mechatronics. 2008;18:434-47.

[6] Choi Y, Cho J, Choi S, Wereley N. Constitutive models of electrorheological and magnetorheological fluids using viscometers. Smart Materials and Structures. 2005;14:1025.

[7] Baranwal D, Deshmukh T. MR-Fluid Technology and Its Application-A Review. International Journal of Emerging Technology and Advanced Engineering. 2012;2:563-9.

[8] Li W, Du H. Design and experimental evaluation of a magnetorheological brake. The International Journal of Advanced Manufacturing Technology. 2003;21:508-15. 
[9] Tan K, Stanway R, Bullough W. Braking responses of inertia/load by using an electro-rheological (ER) brake. Mechatronics. 2007;17:277-89.

[10] Nam TH, Ahn KK. A new structure of a magnetorheological brake with the waveform boundary of a rotary disk. Smart Materials and Structures. 2009; 18:115029.

[11] Li W, Liu B, Kosasih PB, Zhang X. A 2-DOF MR actuator joystick for virtual reality applications. Sensors and Actuators A: Physical. 2007;137:308-20.

[12] Park EJ, Stoikov D, da Luz LF, Suleman A. A performance evaluation of an automotive magnetorheological brake design with a sliding mode controller. Mechatronics. 2006;16:405-16.

[13] Smirnov N, Sabanin V, Repin A. Sensitivity and robust tuning of PID controllers with real differentiation. Thermal Engineering. 2007;54:777-85. 